\title{
Coastal-Trapped Waves with Finite Bottom Friction
}

\author{
K. H. Brink \\ Mail Stop 21 \\ Woods Hole Oceanographic Institution \\ Woods Hole, MA 02543
}

$5 / 15 / 2006$

\begin{abstract}
:
Coastal-trapped waves with finite-amplitude bottom friction are explored. "Finiteamplitude" in this context means that the bottom stresses are large enough to change the wave modal structure. The importance of bottom friction is measured by the nondimensional number $r /(\omega h)$, where $r$ is a bottom resistance coefficient, $\omega$ is the wave frequency and $h$ is the water depth. Increasing bottom drag causes free wave modes to adjust by having their amplitude maxima for alongshore current translate offshore to the point that, with relatively large bottom stress, the alongshore current variance is trapped entirely on the slope, even though pressure variations remain substantial right up to the coast. In conjunction with these adjustments, wave frequency, hence propagation speed, varies and the wave damping is usually less than would be expected based on a weakfriction perturbation calculation. Stronger density stratification increases wave damping, all else being the same. A mean alongshore flow can strongly affect modal structure and wave damping, although general trends are difficult to discern. Results suggest that bottom friction may cause an observed tendency for lower frequency alongshore current fluctuations to become relatively more important with distance offshore.
\end{abstract}




\section{Introduction:}

For many applications of coastal-trapped wave theory, such as hindcasting alongshore currents over the continental shelf, the usual approach is to take advantage of a "long wave" approximation, i.e., to require that typical frequencies are small relative to the inertial, that damping is fairly weak and that alongshore length scales are much greater than those in the cross-shelf direction. In this limit, the wave modes are orthogonal, and hindcasting is fairly straightforward. Although this approach has demonstrated skill for sea level and alongshore currents (e.g., Battisti and Hickey, 1984; Chapman, 1987), there remain deficiencies and open questions. One deficiency is the tendency for many wave calculations to yield alongshore currents that are strongest near the coast, as opposed to an observed maximum farther offshore. Although this result was found off the U.S. west coast (Chapman, 1987: the spatial offset being about $5-10 \mathrm{~km}$ on a $20 \mathrm{~km}$-wide shelf) for example, the effect there could be due to the structure of the wind stress field (Brink et al., 1987). Off Peru, however, this same discrepancy was found in March-May 1977 (Brink et al., 1980 vs. Brink, 1982) even though nearby winds do not play a substantial role in driving alongshore currents. It seems possible that the mid-outer shelf velocity maximum could potentially be due to bottom friction acting on free coastal-trapped waves, as shown by Power et al. (1989) with a simplified barotropic model.

A second class of questions also remains. First mode coastal-trapped waves, with typical periods of O(10days) propagate around the southern coast of Africa and dominate the subtidal sea level variability until they begin to propagate into the energetic poleward Agulhas current where it is close to shore (de Cuevas et al., 1986; Schumann and Brink, 1990). Some have argued that the sudden decrease in propagating variability in this area could be due to a critical flow process where waves are no longer able to propagate upstream (e.g., Gill and Schumann, 1979). Alternatively, Brink (1990) argued that the mean current is not sufficiently strong to stop all propagation and that instead, the relative vorticity of the Agulhas deforms coastal-trapped wave structure so as to increase frictional wave decay radically. However, Brink's (1990) argument was only suggestive because it was based on extrapolating perturbation barotropic results for weak damping.

Given these two problems, it is reasonable to revisit the coastal-trapped wave propagation problem using a new free baroclinic wave model that allows the inclusion of stratification, a mean alongshore flow, finite-amplitude bottom friction and a complex wave frequency. The resulting free, damped, wave modes provide a compact representation of frictional effects on the inviscid (or nearly inviscid) solutions.

Given that continental shelf waters are relatively shallow, bottom frictional effects are expected to play a substantial role in coastal processes. Brink and Allen (1978) introduced bottom friction into a long barotropic wave model, and deduced damping rates and phase changes in the limit of weak dissipation. Inclusion of dissipation at the outset makes the problem inseparable and so leads to a different, complex eigenvalue problem for the free wave modes, and a consequent loss of mathematical orthogonality, hence utility. Brink (1990) developed a small-damping perturbation solution for the imaginary part of frequency (wave damping) for general frequency and wavenumber, and (for the 
barotropic case) including a mean alongshore flow. His results are valid in the limit that the wave modal structure is not substantially modified by friction, as it would be with finite bottom stress. Barotropic, long wave modes with finite damping were explored by Power et al. (1989), who found that as the bottom friction coefficient (the proportionality constant between stress and bottom currents) increases, the modal structures adjust by weakening currents close to the coast and having the strongest currents appear progressively farther offshore, and so decreasing the net wave decay rates relative to what might be expected based on the perturbation results for weak damping. Analogous results were found by Allen (1984) for two-layer coastal-trapped waves, where larger friction coefficients lead to increasingly surface-trapped motions and, eventually, a decrease in net wave damping. Finally, Clarke and Van Gorder (1994) studied alongshore propagation on interannual time scales along a meridional coastline in a $\beta$ plane ocean. They found a similar tendency for bottom friction to force propagating current variance into deeper water offshore, while pressure remains substantial over the shelf and up to the coast.

The specific questions addressed here involve the use of a more general wave model to address how bottom friction affects coastal-trapped wave damping and modal structures. These influences will be shown to depend on the presence of both a mean flow and density stratification.

\section{Formulation:}

Free wave solutions for Boussinesq, hydrostatic, linearized coastal-trapped waves along a straight coast are sought. The offshore direction is $x$ and the vertical direction is $z$, where the origin is at the surface at the coast. The depth $h(x)$ and mean alongshore flow $v_{0}(x, z)$ are uniform in the alongshore $(y)$ direction. Dissipative effects are limited to an infinitesimally thin bottom boundary.

The equations of motion are:

$$
\begin{aligned}
v_{t}+u v_{0 x}+v_{0} v_{y}+w v_{0 z}+f u & =-\rho_{0}{ }^{-1} p_{y}+\rho_{0}{ }^{-1} \tau_{z}^{y} \\
u_{t}+v_{0} u_{y} \quad-f v & =-\rho_{0}{ }^{-1} p_{x}+\rho_{0}{ }^{-1} \tau_{z}^{x} \\
0 & =-p_{z}-g \rho_{2} \\
u_{x}+v_{y}+w_{z} & =0 \\
\rho_{2 t}+u \rho_{1 x}+v_{0} \rho_{2 y}+w \rho_{1 z} & =0,
\end{aligned}
$$

where $u, v, w$ are the perturbation velocity components in the $x, y, z$ directions, respectively, $p$ is perturbation pressure, $f$ is the Coriolis parameter, and density is broken up as: $\rho_{0}+\rho_{1}(x, z)+\rho_{2}(x, y, z, t)$ where $\rho_{0}>>\rho_{1}>>\rho_{2}: \rho_{1}$ is the geostrophically balanced (with $v_{0}(x, z)$ ) background density field and $\rho_{2}$ is the wave perturbation density. 
In all cases, dependent variables subscripted by an independent variable represent partial differentiation. Turbulent vertical stresses in the $x, y$ directions are given by $\tau^{x}, \tau^{y}$, and the bottom stress $\left(\tau_{0}^{x}, \tau_{0}^{y}\right)$ is related to the interior bottom velocity by

$$
\tau_{0}^{x}=\rho_{0} r u_{B}, \quad \tau_{0}^{y}=\rho_{0} r v_{B}
$$

where $r(x)$ is a bottom resistance coefficient having units of velocity, and a subscript " $\mathrm{B}$ " denotes a quantity evaluated at the top of the infinitesimally thin bottom boundary layer. Further,

$$
\begin{aligned}
& N^{2}=-g \rho_{0}{ }^{-1} \rho_{1 z} \quad \text { and } \\
& M^{2}=-g \rho_{0}{ }^{-1} \rho_{l x} .
\end{aligned}
$$

The problem is solved by assuming

$$
p=p(x, y) \exp [i(\omega t+l y)], \text { etc., }
$$

where the frequency $\omega$ can be complex and the alongshore wavenumber $l$ is real. Using this formulation, the problem is reduced to a single partial differential equation for pressure

$$
\begin{aligned}
0=\omega^{\prime} & p_{x x}-2 \omega^{\prime} s p_{x z}+\omega^{\prime} N^{-2}\left(f f^{\prime}-\omega^{\prime 2}\right) p_{z z}-\omega^{\prime}\left(Q+s_{z}\right) p_{x} \\
& -\left[-\omega^{\prime} s Q+\left(\omega^{\prime} s\right)_{x}+l f^{-1} s\left(f^{2}-\omega^{\prime 2}\right)-\left(\omega^{\prime} N^{-2}\right)_{z}\left(f f^{\prime}-\omega^{\prime 2}\right)-\left(\omega^{\prime} N^{-2}\right)\left(s M^{2}\right)_{z}\right] p_{z} \\
& -\left[l f Q+\omega^{\prime} l^{2}+l s_{z}\right] p,
\end{aligned}
$$

where

$$
\begin{aligned}
& \omega^{\prime}=\omega+l v_{0} \\
& s=M^{2} / N^{2} \\
& f^{\prime}=f+v_{0 x} \\
& f^{*}=f+v_{0 x}-M^{2} s / f, \\
& Q=\left(f f^{*}-\omega^{\prime 2}\right)^{-1}\left[\left(f f^{*}-\omega^{\prime 2}\right)_{x}-s\left(f f^{*}-\omega^{\prime 2}\right)_{z}\right] .
\end{aligned}
$$

This equation and the notation are similar to those of Mooers (1975), except that these are for hydrostatic conditions. In the absence of a mean flow, (2.9) reduces to the familiar linearized vorticity equation (e.g., Huthnance, 1978). 
The boundary conditions are as follows:

Surface: The free surface boundary condition is

$$
w=\left(g \rho_{0}\right)^{-1}\left[p_{t}+v_{0} p_{y}\right] \quad \text { at } z=0 .
$$

Bottom: The bottom boundary condition combines the inviscid tendency for no flow through the bottom with the effects of Ekman suction (Brink et al., 1987):

$$
0=w+h_{x} u+U_{E x}+V_{E y}, \quad \text { at } \quad z=-h(x),
$$

where

$$
\begin{aligned}
& U_{E}=r\left(f f^{*}-\omega^{\prime 2}\right)^{-1}\left(-i \omega^{\prime} u-f v\right)_{B}, \\
& V_{E}=r\left(f f^{*}-\omega^{\prime 2}\right)^{-1}\left(f^{*} u-i \omega^{\prime} v\right)_{B} .
\end{aligned}
$$

The simple proportionality of bottom stress to currents (2.6) breaks down in the presence of a strongly sheared mean alongshore flow (e.g., Brink, 1997), but this simpler stress formulation is retained here. It should be at least qualitatively correct for Rossby numbers less than unity. In addition, the combined effects of stratification and bottom slope can act within the bottom boundary layer to neutralize bottom friction in reality, effectively reducing $r$ (e.g., Trowbridge and Lentz, 1991), but this reduction is also not accounted for here.

Coast: The coastal boundary condition requires no net transport through the coastal barrier:

$$
0=U_{E}+\int_{-h}{ }^{0} u d z \approx U_{E}+u h(0),
$$

where the approximation is valid if the coastal wall is low relative to the inherent vertical scales in the flow field. For an inviscid problem $(r=0)$, the condition reduces exactly to $u=0$.

Offshore: Since the model numerical domain is finite, a condition that mimics a boundedness condition must be chosen. Following Brink (1982), the condition

$$
u_{x}=0 \text { at } x=x_{M}
$$

is used, where $x_{M}$ lies well offshore of the shelf-slope topography.

The problem can be nondimensionalized using $\mathrm{H}, \mathrm{L}, \mathrm{V}, \mathrm{N}_{0}$, $\mathrm{f}$ and $\mathrm{r}_{0}$ as representative scales for depth, horizontal distance, mean velocity, stratification, inverse time and bottom resistance coefficient, respectively. The resulting system has four nondimensional parameters,

$$
\mathrm{S}=\left(\mathrm{N}_{0} \mathrm{H}\right)^{2} /(\mathrm{fL})^{2} \text {, the Burger number, }
$$




$$
\begin{aligned}
& \mathrm{D}=(\mathrm{fL})^{2} /(\mathrm{gH}), \text { a surface divergence parameter, } \\
& \mathrm{R}=\mathrm{V} /(\mathrm{fL}), \text { the Rossby number of the mean flow, and } \\
& \mathrm{E}=\mathrm{r}_{0} /(\mathrm{fH}), \text { a form of Ekman number. }
\end{aligned}
$$

Of these parameters, the first two are familiar from Huthnance's (1978) classic analysis. For many coastal problems, the divergence parameter is fairly small and does not play a very important role in the analysis. The Burger number, however, is an important measure of the tendency for the flow to be barotropic (small S, or, effectively wide shelf) or baroclinic (S of $\mathrm{O}(0.1-1)$, or effectively narrow shelf).

The two new parameters have relatively straightforward meanings, although there can be difficulties choosing the natural scales in practice because depth typically varies over a couple orders of magnitude, and the mean velocity may not have the same inherent scales as the topography. The following analysis will be carried out in dimensional form, but the nondimensional numbers are useful for placing results into context.

The above system of equations (2.9-2.15) is transformed to a stretched vertical coordinate, $\theta=z / h(x)$, system, and is then solved numerically using resonance iteration for a complex frequency. The code is written entirely in Matlab ${ }$, and makes use of the simplex minimization algorithm, "fminsearch" to search for complex free wave solutions. Typically, the calculations presented here use 120 grid points in the offshore direction and 30 in the vertical. All solutions have a nominal accuracy of $0.01 \%$ for the absolute value of frequency. The model uses real topography and stratification from offshore of the mean flow. The mean flow can be centered at any depth or location and takes the form of a Gaussian with different upward, downward, onshore and offshore scales. The code is capable of dealing with instability problems under fairly general conditions, and results from this application will be published elsewhere.

Many of the computed examples here use topography, stratification and mean flow representative of a section near $30.5^{\circ} \mathrm{S}$ (south of Durban, South Africa: Figure 6) across the Agulhas current where it flows near the shoreline. This is section " $\mathrm{K}$ " in the notation of Schumann and Brink (1990). The basic mean flow for this section is specified by its maximum of $100 \mathrm{~cm} / \mathrm{sec}$ at the surface at $x=50 \mathrm{~km}$ from the coast. The exponential scales in the downward, offshore and onshore directions are $700 \mathrm{~m}, 50 \mathrm{~km}$ and $30 \mathrm{~km}$, respectively. For simplicity, $f$ is kept positive $\left(7.71 \times 10^{-5} 1 / \mathrm{sec}\right)$ and so the model Agulhas current is positive to be consistent.

\section{Results: No mean flow.}

The effects of damping can be seen in a representative dispersion relation (Figure 1) computed using the South African " $\mathrm{K}$ " topography and offshore stratification, but setting the mean alongshore flow to zero. This is a case where stratification plays a major role $(\mathrm{S}=0.12)$ in determining the wave structure. The real part of frequency $\omega_{R}$ describes the 
rate of wave propagation in the usual way, while the imaginary part of frequency $\omega_{I}$ describes the rate of frictional decay. The ratio of wave kinetic to potential energy in the inviscid case, $\Gamma=1.2$, reflects the near-equipartition expected in the pure internal Kelvin wave limit (by contrast, a purely barotropic shelf or Rossby wave would have $\Gamma=\infty$, if the free surface potential energy were ignored through a rigid lid approximation). The dissipative example in Figure 1 uses a bottom resistance coefficient of $r=0.05 \mathrm{~cm} / \mathrm{sec}$, a value representative of those in the literature. For comparison, the inviscid wave frequencies are also shown (along with the perturbation frictional imaginary part of frequency for $r=0.05 \mathrm{~cm} / \mathrm{sec}$ ). Since this is a case with strong stratification effects, the inviscid solutions are, like an internal Kelvin wave, nearly nondispersive for subinertial frequencies.

Several frictional effects are evident from the results. First, the real part of the dispersion curve shows that dissipation induces dispersion, especially at the lowest frequencies $\left(\omega_{R}\right.$ $<0.3 \times 10^{-5} \mathrm{sec}^{-1}$ ). Frequency initially increases more quickly than the linear nondispersive rate, and then more slowly before settling down to a curve that nearly parallels the inviscid curve. The perturbation (Brink, 1990) imaginary part of frequency (clearly not used validly for such a large value of $r$ ), or dissipation rate, is nearly constant over the range shown here, while the more realistic directly calculated damping rates (imaginary part of the frequency) are generally smaller, especially at intermediate wavenumbers. That is, the perturbation results, which do not account for frictionally induced changes in modal structure, overestimate the wave damping. For frequencies below $0.1 \times 10^{-5} \mathrm{sec}^{-1}$, dissipation rates are greater than real frequencies, so that observable propagation becomes unlikely. Frictional effects thus play a substantial role, but what, physically, causes these changes?

The wave modal structures adjust to bottom stresses so that wave damping is mitigated (relative to extrapolation of the weak damping case), and so the wave's propagation speed is affected. This outcome could be anticipated from the barotropic results of Power et al. (1989), who showed that increasing bottom drag causes modal structures to adjust so that propagating kinetic energy is concentrated in deeper and deeper water, where dissipation relative to water column height (local Ekman number) actually decreases.

One way to gain some perspective on these results is to consider how waves at a fixed wavenumber adapt as the resistance coefficient (or, equivalently, Ekman number) is increased (Figure 2a). For very weak damping $(r=0.001 \mathrm{~cm} / \mathrm{sec})$, the wave modal structure is essentially that of the inviscid limit, and the perturbation damping rate results are valid. The perturbation estimate, which necessarily increases linearly with resistance, is simply the extension of the initial slope of the damping vs. $r$ curve. This extrapolated estimate is always greater than the calculated damping rate (Figure 2b), so it appears (from this and results below) that frictionally induced adjustments in modal structures act, in general, to mitigate wave decay. However, the amount of mitigation will be shown to be a function of stratification, mean flow and topography.

As in the barotropic (Power et al., 1989) case, the present baroclinic wave mode adjusts to stronger damping by having the strongest modal alongshore currents move offshore 
into deeper water (Figure 3, left panels). At the same time, pressure (Figure 3, right panels) inshore of the current maximum becomes relatively uniform in the cross-shelf direction so that a wave would remain detectable in coastal sea level even if currents over the shelf were weak. Initially, the velocity structural change leads to weaker damping when the net volume of water affected by bottom friction increases. However, as the velocity peak moves into deeper water, the wave becomes bottom trapped with a vertical length scale (from scaling 2.9 with no mean flow) of order $(f / N) L$, where $L$ is typically the width of the continental slope for this application. Because of this bottom trapping, the volume of water affected by bottom stress does not increase substantially as the wave "slides" into deeper water. Hence, to the extent stratification is important, it tends to enhance the role of bottom stress relative to a barotropic case, where the relevant vertical scale is always the total water depth (which does increase offshore). On the other hand, as stratification (or S) is decreased substantially, bottom trapping is much less severe, and so the wave structure still tends to occupy most of the water column as the velocity maximum moves offshore. Consequently, the decrease in damping (relative to the perturbation results: Figure $2 \mathrm{~b}$ ) is much greater when the effects of stratification are weak. As a result, the perturbation wave damping rates are less inaccurate if stratification is important, even though modal structures change substantially as a function of $r$ in any case.

Returning now to the frictional dispersion curve (Figure 1, real part), the results are more understandable. Modal structures for both longer (Figure 4a) and shorter wavelengths (Figure 4b) are strongly bottom trapped, but over the lower slope or upper slope, respectively. This gravest coastal-trapped wave mode would, without damping, have its first mode velocity variance trapped mainly over the shelf (similar to Figure 3a, which has very weak damping). Thus, the modal structures are all very strongly affected by damping, so that the wave becomes a damped bottom-trapped mode (having some features in common with the inviscid waves of Rhines, 1970) on the upper and lower slopes. Differences in slope and stratification with depth thus appear to account for whether the real part of frequency falls above or below the dispersion curve for the rather different, shelf-trapped inviscid wave modes. For much shorter wavelengths (higher real frequencies: $l=1 \times 10^{-7} \mathrm{~cm}^{-1}, \omega=2.97 \times 10^{-5}+i 1.74 \times 10^{-6} \mathrm{sec}^{-1}$ ), the modal structure is extremely similar to that for the inviscid case, and the real frequencies agree to within about $1 \%$. Thus, for a fixed stratification, the importance of dissipation depends strongly on both the bottom resistance coefficient and on the frequency. This dependence can be readily rationalized by nondimensionalizing the coastal boundary condition (2.14). The importance of friction is then seen to depend upon

$$
\left(\sigma d_{C}\right)^{-1} \mathrm{E}=r /[\omega h(0)]
$$

where $\sigma$ is the nondimensional wave frequency and $d_{C}$ is the nondimensional depth at the coast.

A second geographic example treats the western coast of Australia, where the shelf is physically shallow $(50 \mathrm{~m})$ and quite wide, about $75 \mathrm{~km}$ and $\mathrm{S}=0.07$. The example is based on the Dongara mooring line (Smith et al., 1991) at $29.5^{\circ} \mathrm{S}$. Results are presented 
in the form of dispersion curves (Figure 5), comparable to Figure 1. For small wavenumbers (low frequency), the frictional, $r=0.05 \mathrm{~cm} / \mathrm{sec}$, dispersion curves look very similar to the Agulhas case, in that the real part of frequency does not obviously tend toward zero, and that the imaginary part first decreases and then increases with wavenumber (decreasing alongshore scales). At higher frequencies, however, the real part of frictional frequency diverges dramatically from the nondissipative case, unlike the narrow shelf case. The perturbation estimate of $\omega_{I}$ is far too large at all wavenumbers. The reason is straightforward. Over the shelf, at these frequencies, $r /(\omega h)$ is everywhere $>0.67$. That is to say that damping is very strong everywhere on the shelf, and the modal structures (not shown) adjust so that alongshore velocity over the shelf approaches zero while the shelf pressure approaches a constant. Physically, then, the shelf plays a passive role, and the effective coastal boundary moves offshore to an isobath deeper than about $50 \mathrm{~m}$. The remaining wave is then associated with the fairly narrow, $\mathrm{O}(90 \mathrm{~km})$ offshore remainder of the shelf-slope topography. This narrow topography in turn is consistent with much slower wave propagation. This finding is anticipated by the analysis of Mitchum and Clarke (1986) who advocated placing coastal-trapped wave nearshore boundaries on the isobath where the water depth is equal to three times the Ekman scale depth, or roughly where $h=6 r / f(=43 \mathrm{~m}$ for $r=0.05 \mathrm{~cm} / \mathrm{sec})$ in the present notation. Experimentation here suggests that four times the scale depth $(56 \mathrm{~m})$ would be a better, but still imperfect, choice at least for estimating the damping rate. Other than this offshore displacement of the effective coastal location, the wide shelf results are consistent with the South African example in that, with increasing bottom friction, the wave modal structure becomes increasingly concentrated in deeper water so that perturbation dissipation estimates are always too high.

\section{Results: With mean alongshore flow.}

The effects of a mean alongshore flow are explored by considering section $\mathrm{K}$ conditions representative of the Agulhas current off of the coast of KwaZulu-Natal, South Africa (Figure 6). Complex wave frequency as a function of the bottom resistance parameter $r$ for a fixed alongshore wavenumber (Figure 7) again illustrates key results. The most obvious mean flow effect is Doppler shifting: with a flow in the direction of free coastaltrapped wave propagation (opposite to the Agulhas), the real part of wave frequency increases, and, when flow opposes free wave propagation (the sense of the Agulhas), the frequency decreases (Figure 7).

The wave damping in this example depends strongly on the sense of the flow. When the flow is reinforcing or nil, results are similar: the imaginary part of frequency increases fairly slowly with $r$, and the directly computed damping is far less than that predicted by the perturbation theory (the perturbation result can be visualized as the line tangent to the $\omega_{I}$ curve at $r=0$ ). This is as expected from section 3 . However, with mean flow opposed to wave propagation (the realistic case for the Agulhas), wave damping increases nearly linearly with resistance coefficient, so that the perturbation result for damping is a fair estimate for the entire range represented. Damping is so strong that, for this wavenumber, free wave propagation practically ceases $(e$-folding distance of $690 \mathrm{~km}$ for $l=1 \times 10^{-8} \mathrm{~cm}^{-1}$ and $r=0.05 \mathrm{~cm} / \mathrm{sec}$ ), although the decay distance does increase by 
somewhat more than about $20 \%$ as wavenumber increases by an order of magnitude. Thus, the presence of the Agulhas greatly increases net wave damping relative to the case of no mean flow.

Why should this be? The inviscid alongshore velocity modal structures differ considerably depending on the sign of the mean flow (Figure 8). When flow is in the direction of free waves, the modal structure extends far off the shelf, but with flow counter to wave propagation, the flow concentrates strongly onto the shelf. Concentrating wave variance over the shelf makes the wave more susceptible to damping since there are relatively stronger currents and less volume of moving water to spin down for a given stress. This tendency can be crudely quantified by computing for each mode the area over which the magnitude of alongshore velocity exceeds $20 \%$ of the maximum magnitude. For the examples of inviscid wave modes with Agulhas, quiescent and antiAgulhas flow, the areas are 7,16 and $33 \mathrm{~km}^{2}$, respectively. As $r$ is increased, the wave mode for the Agulhas (opposing) flow remains tightly bunched, e.g., for $r=0.04 \mathrm{~cm} / \mathrm{sec}$, the areas are 4, 19 and $24 \mathrm{~km}^{2}$, respectively. The apparent reason for this compressed modal structure is the mean potential vorticity gradient: for the Agulhas example, the mean flow potential vorticity gradient $v_{0 x x} / h$ is comparable in magnitude- $\mathrm{O}\left(2 \times 10^{-16}\right.$ (sec $\left.\left.\mathrm{cm}^{2}\right)^{-1}\right)$ to the topographic potential vorticity gradient, $\left.-f h_{x} / h^{2}-\mathrm{O}\left(-6 \times 10^{-16}(\mathrm{sec} \mathrm{cm})^{2}\right)^{-1}\right)$ and opposes it at the shelf edge, while reinforcing it near the jet core.

The examples in Figures 2 and 7 all show the real part of wave frequency initially decreasing as the friction coefficient increases. This is not always the case. For example, in the Agulhas-like case where flow opposes wave propagation, the second wave mode frequency (not shown) increases with $r$ over the whole range from $r=0$ to $0.12 \mathrm{~cm} / \mathrm{sec}$. The difference is likely associated with the second mode's more complex spatial structure.

The Agulhas example shows that an opposing mean current causes a substantial increase in coastal-trapped wave damping. Is this result to be expected in general? A comparable situation is found in the United States South Atlantic Bight, where the Gulf Stream also flows in the sense opposite to free wave propagation. This case is treated using parameters adapted from Luther and Bane (1985). Relative to southeastern Africa, the Gulf Stream case should have more barotropic waves overall, since the Burger number is smaller than for the Agulhas example ( $\mathrm{S}=0.03$ vs. 0.12 , respectively). For the South Atlantic Bight case (Figure 9), the real wave frequency decreases monotonically with $r$ (both with and without a mean flow), as in the South African case with $v_{0}=0$ and decreasing stratification (Figure 2). Damping is somewhat enhanced by the Gulf Stream mean flow for $r<0.05 \mathrm{~cm} / \mathrm{sec}$, but the reduction in damping relative to the perturbation results is greater in the presence of a mean flow than in a quiescent ocean. Thus, because a western boundary current-type mean flow does not always enhance damping, the Agulhas results are thus not general.

The main conclusion from the above is that coastal-trapped wave damping and modal structure can be substantially affected by a mean alongshore flow, but the sense and 
magnitude of the changes depend sufficiently on the details of the mean fields that generalizations are difficult.

\section{Discussion}

Including bottom friction at lowest order in a coastal-trapped wave model changes the results in several ways. Although wave damping generally increases as the bottom frictional coefficient increases, it does so less strongly (often, much less strongly) than would be expected from a weak-friction perturbation result. This mitigation happens because, with increasing bottom resistance, the wave modal structure adjusts to move the maximum in wave alongshore current variance farther and farther offshore. As this happens, frictional influences are distributed over a larger water volume (limited by either the total water depth or the bottom trapping scale, whichever is less), and so wave decay becomes relatively less. At higher frequencies, adjustment is not as strong, consistent with the overall importance of bottom friction scaling as $\left(\sigma d_{C}\right)^{-1} \mathrm{E}$. The effectiveness of this mitigation by wave structural change is greater for cases with weaker ambient density stratification (smaller S). Although the wave velocity amplitude maximum moves offshore with increasing friction, the pressure field over the shelf for low modes adjusts to a fairly constant (in $x, z$ ) value, so that coastal sea level still reflects trapped current variability, albeit at positions farther and farther offshore.

A mean alongshore current can greatly increase the damping of a particular wave, but this outcome depends strongly on the specifics of the mean current, stratification and topography.

Over a sloping bottom, buoyancy-induced bottom boundary layer arrest (e.g., Trowbridge and Lentz, 1991) should counteract the tendency for friction to have its strongest effects at lowest frequency. One might expect instead that for coastal-trapped wave periods long compared to the time it takes for buoyancy to halt Ekman transport, wave damping should approach zero. For wave periods short relative to the shut-down time, bottom stress would be expected to be largely unaffected by buoyancy effects. Chapman (2002), however, points out that the situation is not this simple because partial shut-down can apparently be found on shorter time scales than a simple scaling argument might suggest. Thus, a straightforward approach to accounting for boundary layer shut-down physics in the present coastal-trapped wave model is elusive.

The results of sections 3 and 4 suggest that the shelf and slope topography acts as a natural temporal filter for alongshore current and sea level changes. At lower frequencies, $\left(\sigma d_{C}\right)^{-1} \mathrm{E}$ is larger, the effect of friction is greater and the wave modal structure has its maximum increasingly farther offshore (e.g., Figure 4). Currents over the shelf become increasingly quiescent as frequency decreases. Thus, given a spectrum of incoming energy, shelf currents ought to be typified by shorter independence time scales (integral of the autocorrelation from 0 to infinity) than those measured farther offshore where lower frequency variability is permitted, hence relatively more important. For bottom pressure, that is not attenuated over the shelf but that has increasingly large offshore extension at lower frequencies, time scales also ought to become longer 
offshore, but in this case it would be because of the relative absence of higher frequency variability farther offshore. If one thinks of wind-driven alongshore currents as a superposition of almost free waves, similar results also ought to apply to wind-forced currents and bottom pressure.

As a test of the filtering notion, independence time scales are computed from demeaned, detrended low-pass filtered alongshore currents over the Peruvian shelf and slope near $15^{\circ} \mathrm{S}$ (Brink et al., 1978), where $\mathrm{S}=0.5$. Peru is a good setting to consider because of its relative absence of known mesoscale activity offshore. Only the 70-day long May-July 1976 records are long enough to obtain reliable results. During this period, alongshore currents were not well correlated with the local alongshore winds. The two moorings in place at that time (one over the shelf and one over the slope) lay along an onshoreoffshore line, and both span roughly the lower $75 \%$ of their water column. In order to compare results compactly, time scales are computed for the first Empirical Orthogonal Function for alongshore velocity at each mooring. These modes both represent at least $70 \%$ of the local variance (Table I), both have their highest amplitudes at shallower depths and neither has a flow reversal with depth. Time scales range from 1.7 days in $128 \mathrm{~m}$ of water to 4.6 days over the slope in $465 \mathrm{~m}$. Similarly, northern California empirical modes for CODE-2 (Winant et al., 1987; $\mathrm{S}=0.09$ ) 113-day long alongshore velocity records were computed (Table I): the modes from the four $\mathrm{C}$-line moorings have similar properties to those for the Peru moorings and an offshore progression of time scales from 1.7 days (C2: $60 \mathrm{~m}$ depth) near the coast to 3.4 days over the slope (C5: 400 $\mathrm{m})$. The second slope mode was more bottom-intensified than the first and had a slightly longer time scale: 3.6 days. The CODE records represent a more clearly wind-driven domain than Peru, so they should be treated with greater caution. A third example, from the physically wide shelf off western Australia is less encouraging. In this case, the time scales for shelf and slope modes are similar, with the shelf time scale being slightly longer (Table I). Inspection of the autospectra show that the difference occurs because of variability at periods longer than 50 days: otherwise, the slope mode's spectrum is "redder", as expected. This outcome apparently reflects the presence of substantial mesoscale eddy activity offshore of the Dongara line (Stammer, 1997; Feng et al., 2005), an effect not accounted for in the present theory. Other potential data sets for evaluation of the filtering conjecture were also sought, but the available long, coincident shelf and slope mooring deployments were generally in locations of substantial offshore mesoscale variability (e.g., Freeland et al., 1986; Nowlin et al., 2005)

These observational results are somewhat consistent with the effects of bottom frictional modal modification, but far from conclusive. A stronger test would call for a more careful calculation that takes into account buoyancy and the frequency, amplitudes and structures of incoming coastal-trapped wave modes. Further, other possibilities (such as the onshore penetration of open ocean mesoscale features) would need to be addressed. Nonetheless, the observed occurrence of lower frequencies being more important in deeper water at least leaves open the possibility that the present frictional filtering concept is valid and that boundary layer damping remains at least somewhat effective despite the potential for boundary layer shut-down. 
Finally, does the finite-damping model account for the rapid decay of coastal-trapped waves off eastern South Africa? Yes, at least partially. For a reasonable resistance coefficient of $0.05 \mathrm{~cm} / \mathrm{sec}$, the wave decay distance (depending on frequency) is in the range of about $690-900 \mathrm{~km}$. While this is a fairly rapid decay rate (and much enhanced

over the case with no mean flow: Figure 7), it does not appear to be quite short enough to account for all of the observed disappearance of the coastal-trapped wave energy over an alongshore distance of about $500 \mathrm{~km}$. Perhaps, given the uncertainty in estimating the friction parameter $r$, this is sufficiently good agreement. The alternative hypothesis (Gill and Schumann, 1979) is that wave propagation is prevented through a critical flow condition. However, at least one upstream-propagating wave mode, with speed about 250 $\mathrm{cm} / \mathrm{sec}$ or less, is calculated to exist, so that the gravest coastal-trapped wave modes can not disappear because a critical flow condition is reached. In conclusion, of the two explanations for why coastal-trapped waves do not reach Durban, enhanced frictional decay now seems the most credible.

\section{Acknowledgements:}

Steve Lentz provided helpful comments on this work. This work was supported by National Science Foundation grant number OCE02-27679.

\section{References:}

Allen, J.S., 1984. A simple model for stratified shelf flow fields with bottom friction. Journal of Physical Oceanography, 14(7), 1200-1214.

Battisti, D.S., and B.M. Hickey, 1984. Application of remote wind-forced coastaltrapped wave theory to the Oregon and Washington coasts. Journal of Physical Oceanography, 14, 887-903.

Brink, K.H., 1982. A comparison of long coastal trapped wave theory with observations off Peru. Journal of Physical Oceanography, 12(8), 897-913.

Brink, K. H., 1990. On the damping of free coastal-trapped waves. Journal of Physical Oceanography, 20(8), 1219-1225.

Brink, K. H., 1997. Time-dependent motions and the nonlinear bottom Ekman layer. Journal of Marine Research, 55(4), 613-631.

Brink, K. H., and J. S. Allen, 1978. On the effect of bottom friction on barotropic motion over the continental shelf. Journal of Physical Oceanography, 8(5), 919-922.

Brink, K.H., J.S. Allen, and R.L. Smith, 1978. A study of low-frequency fluctuations near the Peru coast. Journal of Physical Oceanography, 8(6), 1025-1041. 
Brink, K. H., D. C. Chapman, and G. R. Halliwell, Jr., 1987. A stochastic model for wind-driven currents over the continental shelf. Journal of Geophysical Research, 92(C2), 1783-1797.

Brink, K. H., D. Halpern, and R. L. Smith, 1980. Circulation in the Peruvian upwelling system near $15^{\circ} \mathrm{S}$. Journal of Geophysical Research, 85(C7), 4036-4048.

Chapman, D.C., 1987. Application of coastal-trapped wave theory along the California coast. Journal of Geophysical Research, 92(C2), 1798-1816.

Chapman, D.C., 2002. Deceleration of a finite-width, stratified current over a sloping bottom: frictional spindown or buoyancy shutdown? Journal of Physical Oceanography, 32, 336-352.

Clarke, A.J., and S. Van Gorder, 1994. On ENSO coastal currents and sea levels. Journal of Physical Oceanography, 24(3), 661-680.

De Cuevas, B.A., G.B. Brundrit, and A.M. Shipley, 1986. Low-frequency sea-level fluctuations along the coasts of Namibia and South Africa. Geophys. J. R. Soc., 87, $33-42$.

Feng, M., S. Wijffels, S. Godfrey and G. Meyers, 2005: Do eddies play a role in the momentum balance of the Leeuwin Current? J. Phys. Oceanogr., 35(6), 964-975.

Freeland, H.J., F.M. Boland, J.A. Church, A.J. Clarke, A.M.G. Forbes, A. Huyer, R.L. Smith, R.O.R.Y. Thompson and N.J. White, 1986: The Australian Coastal Experiment: a search for coastal-trapped waves. J. Phys. Oceanogr., 16(7), 12301249.

Gill, A.E., and E.H. Schumann, 1979. Topographically induced changes in the structure of an inertial coastal jet: application to the Agulhas current. Journal of Physical Oceanography, 9(5), 975-991.

Huthnance, J.M., 1978. On coastal trapped waves: analysis and numerical calculation by inverse iteration. Journal of Physical Oceanography, 8(1), 74-92.

Luther, M.E., and J.M. Bane, 1985. Mixed instabilities in the Gulf Stream over the continental slope. Journal of Physical Oceanography, 15(1), 3-23.

Mitchum, G.T. and A.J. Clarke, 1986: The frictional nearshore response to forcing by synoptic scale winds. J.Phys. Oceanogr., 16(5), 934-946.

Mooers, C.N.K., 1975. Several effects of a baroclinic current on the three-dimensional propagation of inertial-internal waves. Geophysical Fluid Dynamics, 6, 277-284.

Nowlin, W.D., A.E. Jochens, S.F. DiMarco, R.O. Reid and M.K. Howard, 2005: Lowfrequency circulation over the Texas-Louisiana continental shelf. In: Circulation in the Gulf of Mexico: Observations and Models (W. Sturges and A. Lugo-Fernandez, editors), Geophysical Monograph Series, American Geophysical Union, Washington D.C., 219-240. 
Power, S.B, J.H. Middleton, and R.H.J. Grimshaw, 1989. Frictionally modified continental shelf waves and the subinertial response to wind and deep-sea forcing. Journal of Physical Oceanography, 19(10), 1486-1506.

Rhines, P.B., 1970. Edge-, Bottom-, and Rossby waves in a rotating stratified fluid. Geophysical Fluid Dynamics, 1, 273-302.

Schumann, E. H., and K. H. Brink, 1990. Coastal-trapped waves off the coast of South Africa: generation, propagation and current structures. Journal of Physical Oceanography, 20(18), 1206-1218.

Smith, R.L., A. Huyer, J.S. Godfrey and J.A. Church, 1991: The Leeuwin Current off western Australia, J. Phys. Oceanogr., 21(2), 323-345.

Stammer, D., 1997: Global characteristics of ocean variability estimated from regional TOPEX/POSEIDON altimeter measurements. J. Phys. Oceanogr., 27(8), 1743-1769.

Trowbridge, J.H., and S.J. Lentz, 1991. Asymmetric behavior of an oceanic boundary layer above a sloping bottom. Journal of Physical Oceanography, 21(8), 1171-1185.

Winant, C.D., R.C. Beardsley and R.E. Davis, 1987: Moored wind, current and temperature observations on the northern California continental shelf during the Coastal Ocean Dynamics Experiment. J. Geophys. Res., 92(C2), 1569-1604. 
Table 1: Independence time scales for empirical orthogonal function mode 1 of alongshore currents.

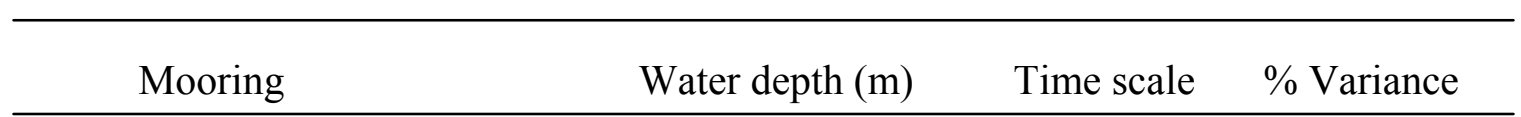

Off Peru, near $15^{\circ} \mathrm{S}$, May-July $1976(\mathrm{~S}=0.5)$ :

$\begin{array}{llll}\text { Mila II } & 128 \mathrm{~m} & 1.7 \text { days } & 92 \% \\ \text { Lagarta } & 465 \mathrm{~m} & 4.6 \text { days } & 74 \%\end{array}$

Off California, near 38.5 $\mathrm{N}$, March-August, 1982 ( $\mathrm{S}=0.09$ ):

$\begin{array}{llll}\mathrm{C} 2 & 60 \mathrm{~m} & 1.7 \text { days } & 91 \% \\ \mathrm{C} 3 & 90 \mathrm{~m} & 1.9 \text { days } & 94 \% \\ \mathrm{C} 4 & 130 \mathrm{~m} & 2.3 \text { days } & 81 \% \\ \mathrm{C} 5 & 400 \mathrm{~m} & 3.4 \text { days } & 68 \%\end{array}$

Off western Australia near 29.5 S, September, 1986- August, 1987 ( $\mathrm{S}=0.07)$ :

$\begin{array}{llll}\text { D2 } & 108 \mathrm{~m} & 4.8 \text { days } & 91 \% \\ \text { D4 } & 704 \mathrm{~m} & 4.5 \text { days } & 79 \%\end{array}$




\section{Figures Captions:}

Figure 1: First mode dispersion curves with $r=0.05 \mathrm{~cm} / \mathrm{sec}$ for stratification and topography representative of section K off southeastern Africa (between Port Elizabeth and Durban) with no mean alongshore flow. Perturbation results are shown by a dotted line. For the calculated results, the real part of frequency $\omega_{R}$ is shown as a solid line, and the imaginary part of frequency $\omega_{I}$ as a dashed line. The circles mark the frequencies for the wave modes shown in Figure 4.

Figure 2: (a) Real part of frequency for the first coastal trapped wave mode as a function of bottom resistance parameter, $r$, for southeastern Africa section $\mathrm{K}$ with no mean alongshore flow and $l=1 \times 10^{-8} \mathrm{~cm}^{-1}$. Real parts of frequency are shown as solid lines, and imaginary are dashed. The different cases correspond to realistic stratification, and for the same $N^{2}$ scaled down by a factor of 10 or 100. (b) Calculated imaginary part of frequency (from Figure 2a) normalized by perturbation damping estimates for the three different stratifications: the observed value $\left(N^{2}\right)$, and values weakened by a factor of 10 $\left(N^{2} / 10\right)$ and $100\left(N^{2} / 100\right)$.

Figure 3: First mode coastal trapped wave alongshore velocity (left) and pressure (right) modal structures for $l=1 \times 10^{-8} \mathrm{~cm}^{-1}$ and (a) $r=0.001 \mathrm{~cm} / \mathrm{sec}$, (b) $r=0.03 \mathrm{~cm} / \mathrm{sec}$, and (c) $r=0.1 \mathrm{~cm} / \mathrm{sec}$. Modes were computed for southeastern Africa section $\mathrm{K}$ and no mean flow. Amplitude is shown as filled contours, and phase by dashed contours. Amplitudes are arbitrary.

Figure 4: First mode alongshore velocity modal structures for southeastern Africa section $\mathrm{K}$ with no mean alongshore flow, and $r=0.05 \mathrm{~cm} / \mathrm{sec}$. The values used here are shown as small circles on Figure 1. (a) $\omega_{R}=7.59 \times 10^{-7} \mathrm{sec}^{-1}, \omega_{I}=10.42 \times 10^{-7} \mathrm{sec}^{-1}$ and $l=1 \times 10^{-9} \mathrm{~cm}^{-1}$. (b) $\omega_{R}=44.76 \times 10^{-7} \mathrm{sec}^{-1}, \omega_{I}=8.48 \times 10^{-7} \mathrm{sec}^{-1}$ and $l=16 \times$ $10^{-9} \mathrm{~cm}^{-1}$.

Figure 5: First mode dispersion curves with $r=0.05 \mathrm{~cm} / \mathrm{sec}$ for stratification and topography representative of the Dongara line west of Australia with no mean alongshore flow. Perturbation results are shown by a dotted line. For the calculated results, the real part of frequency $\omega_{R}$ is shown as a solid line, and the imaginary part of frequency $\omega_{I}$ as a dashed line.

Figure 6: Mean stratification ( $\sigma_{t}$ units minus a constant background) and mean alongshore velocity $(\mathrm{cm} / \mathrm{sec})$ for conditions representative of southeastern African section K (velocity is opposite to the true Agulhas so as to compensate for the use of $f>0)$.

Figure 7: First mode wave frequency for $l=1 \times 10^{-8} \mathrm{~cm}^{-1}$ as a function of resistance parameter $r$ for mean alongshore flow opposed to wave propagation ("Agulhas case"), no mean flow, and mean flow in the same direction ("reversed mean flow") as coastal-trapped wave propagation. Real part of frequency $\omega_{R}$ is shown by solid lines, and imaginary part $\omega_{I}$ by dashed lines. 
Figure 8: First mode alongshore velocity modal structures for $r=0, l=1 \times 10^{-8} \mathrm{~cm}^{-1}$, and conditions representative of southeastern Africa line. The plotting convention is as in Figure 3. (a) with mean flow as in Figure 6, opposed to coastal trapped wave propagation; (b) with mean flow opposite to that in Figure 6, i.e., in the same direction as coastal-trapped wave propagation.

Figure 9: First mode wave frequency as a function of bottom resistance parameter $r$ for conditions representative of the U.S. South Atlantic Bight and $l=1 \times 10^{-8} \mathrm{~cm}^{-1}$. Results are shown for no mean alongshore flow, and with a Gulf Stream present. Solid lines are the real part of frequency $\omega_{R}$, and dashed lines for the imaginary part of frequency $\omega_{I}$. 


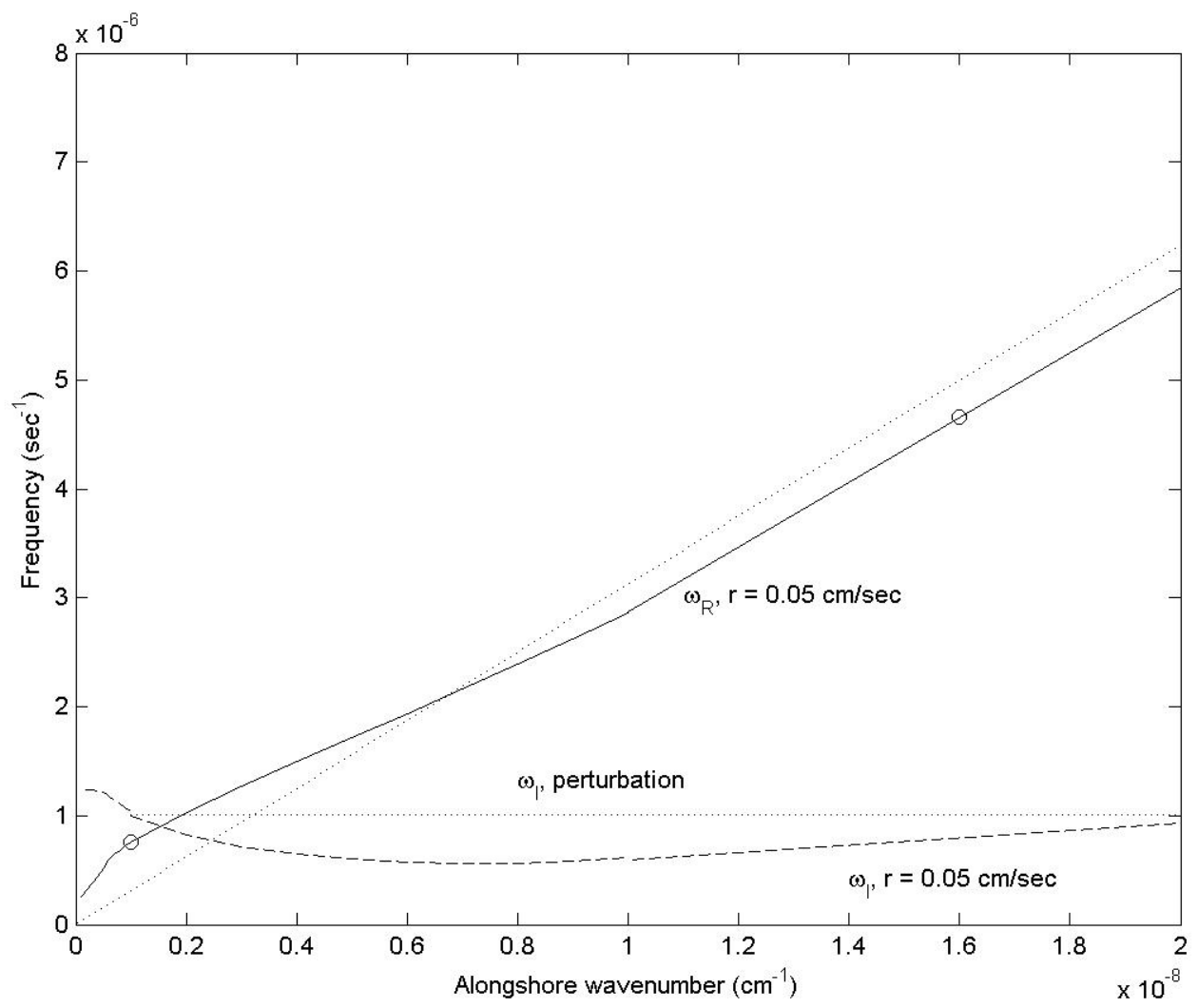

Figure 1: First mode dispersion curves with $r=0.05 \mathrm{~cm} / \mathrm{sec}$ for stratification and topography representative of section K off southeastern Africa (between Port Elizabeth and Durban) with no mean alongshore flow. Perturbation results are shown by a dotted line. For the calculated results, the real part of frequency $\omega_{R}$ is shown as a solid line, and the imaginary part of frequency $\omega_{I}$ as a dashed line. The circles mark the frequencies for the wave modes shown in Figure 4. 


\section{a)}

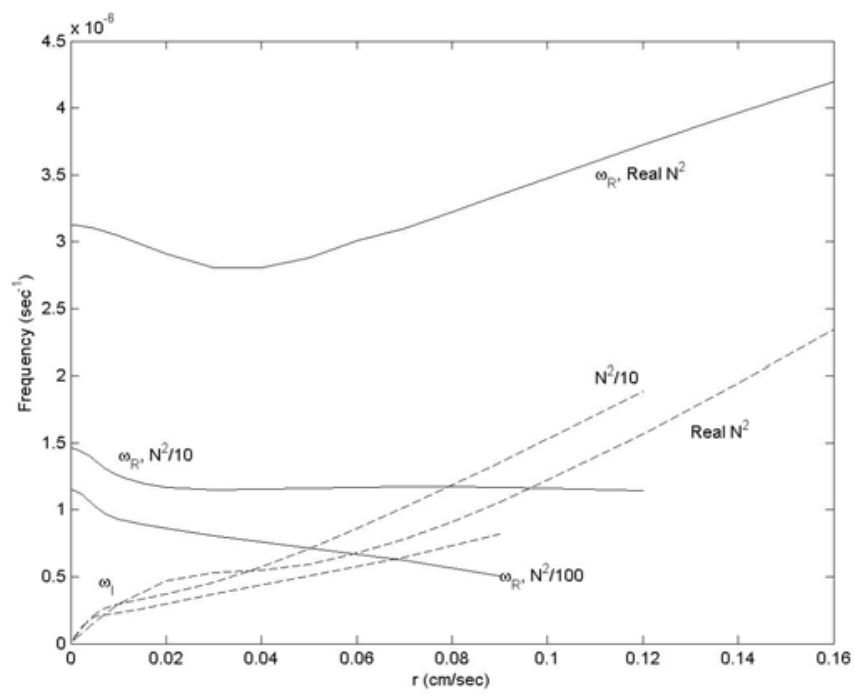

b)

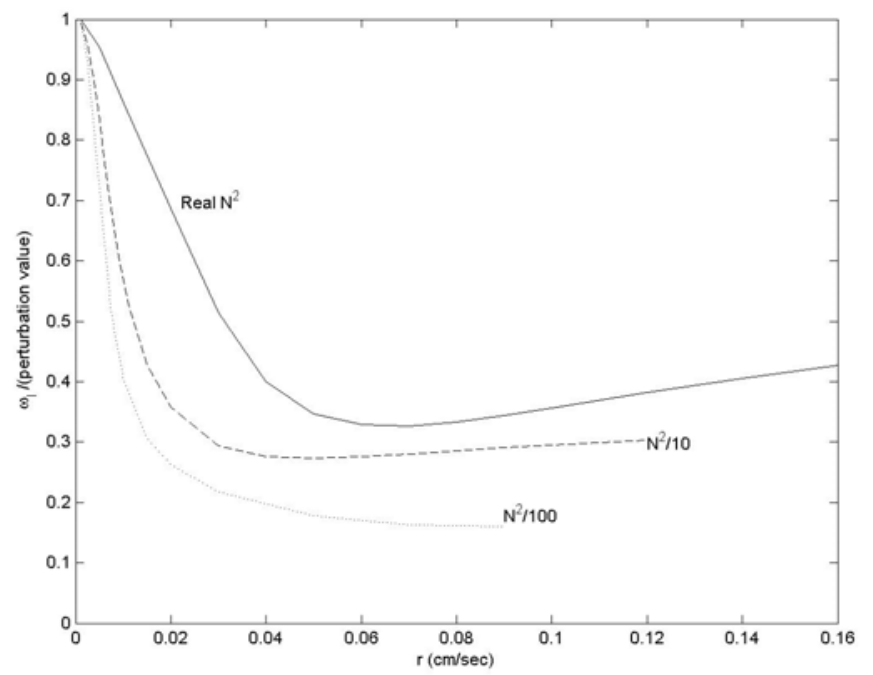

Figure 2: (a) Real part of frequency for the first coastal trapped wave mode as a function of bottom resistance parameter, $r$, for southeastern Africa section $\mathrm{K}$ with no mean alongshore flow and $l=1 \times 10^{-8} \mathrm{~cm}^{-1}$. Real parts of frequency are shown as solid lines, and imaginary are dashed. The different cases correspond to realistic stratification, and for the same $N^{2}$ scaled down by a factor of 10 or 100. (b) Calculated imaginary part of frequency (from Figure 2a) normalized by perturbation damping estimates for the three different stratifications: the observed value $\left(N^{2}\right)$, and values weakened by a factor of 10 $\left(N^{2} / 10\right)$ and $100\left(N^{2} / 100\right)$. 
a)

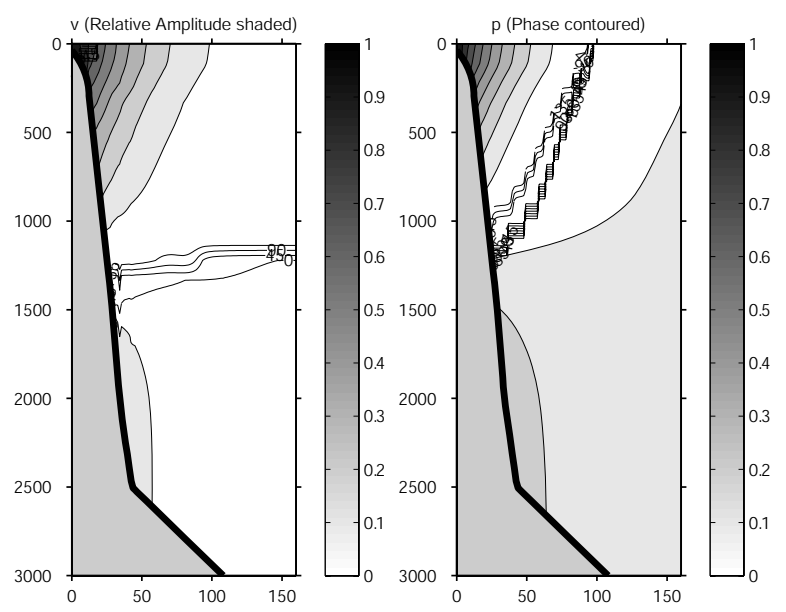

b)
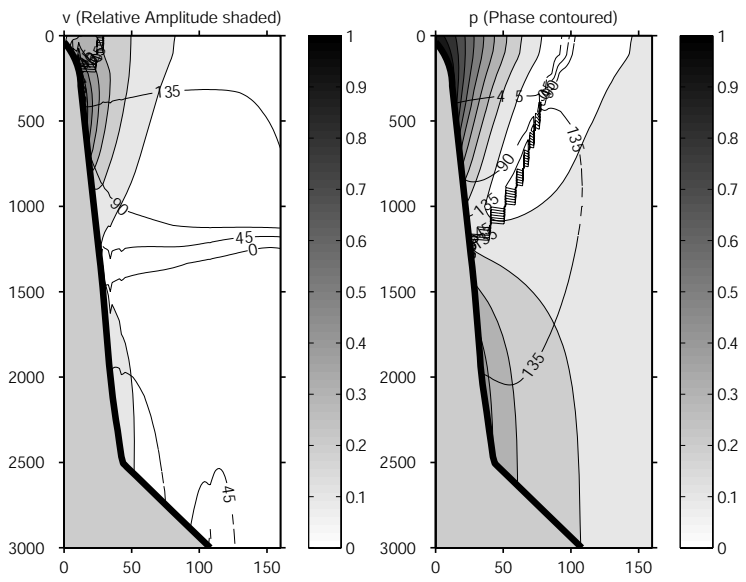

c)
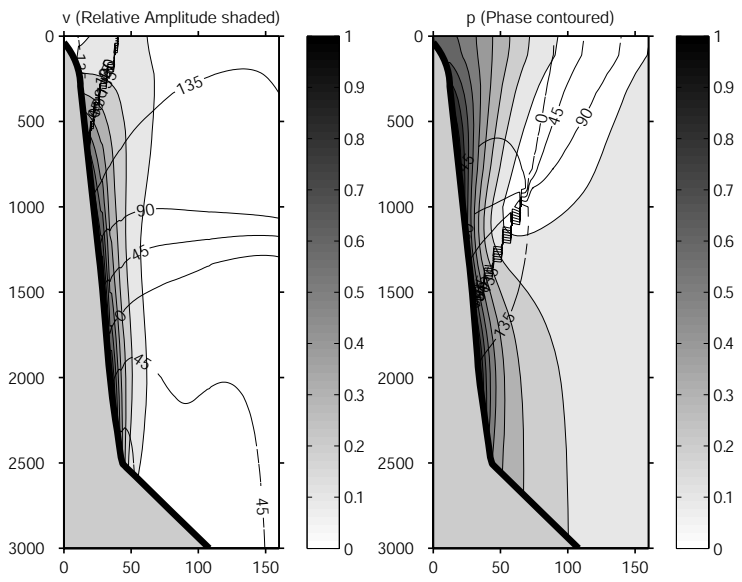

Figure 3: First mode coastal trapped wave alongshore velocity (left) and pressure (right) modal structures for $l=1 \times 10^{-8} \mathrm{~cm}^{-1}$ and (a) $r=0.001 \mathrm{~cm} / \mathrm{sec}$, (b) $r=0.03 \mathrm{~cm} / \mathrm{sec}$, and (c) $r=0.1$ $\mathrm{cm} / \mathrm{sec}$. Modes were computed for southeastern Africa section $\mathrm{K}$ and no mean flow. Amplitude is shown as filled contours, and phase by dashed contours. Amplitudes are arbitrary. 
a)

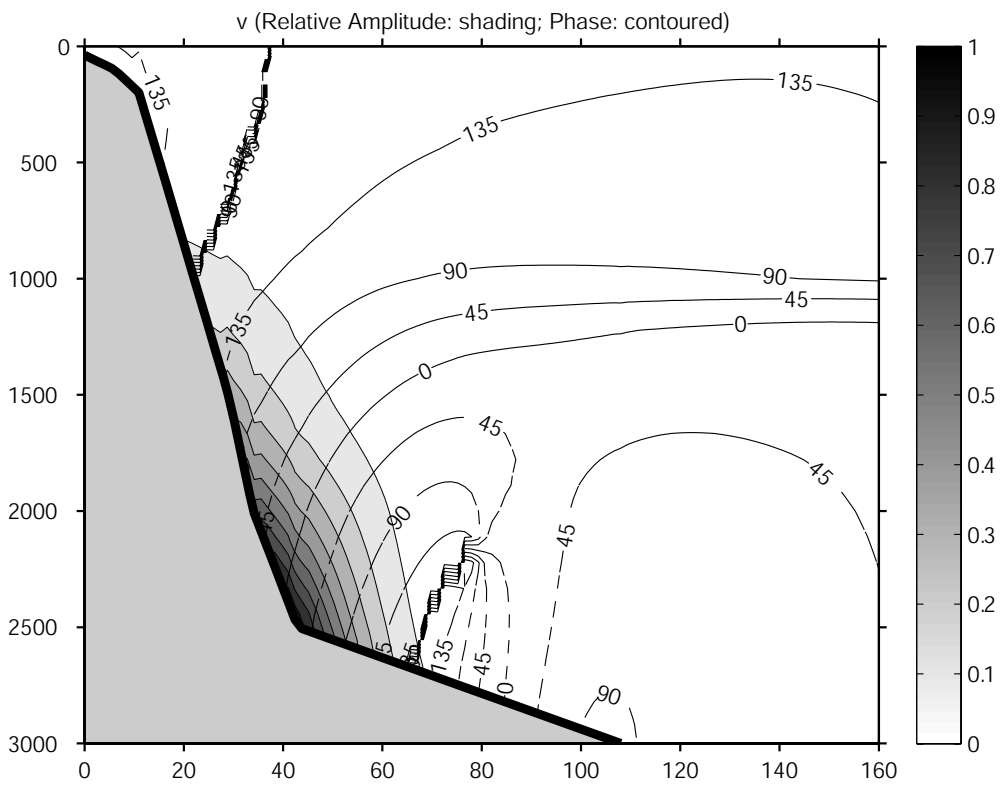

b)

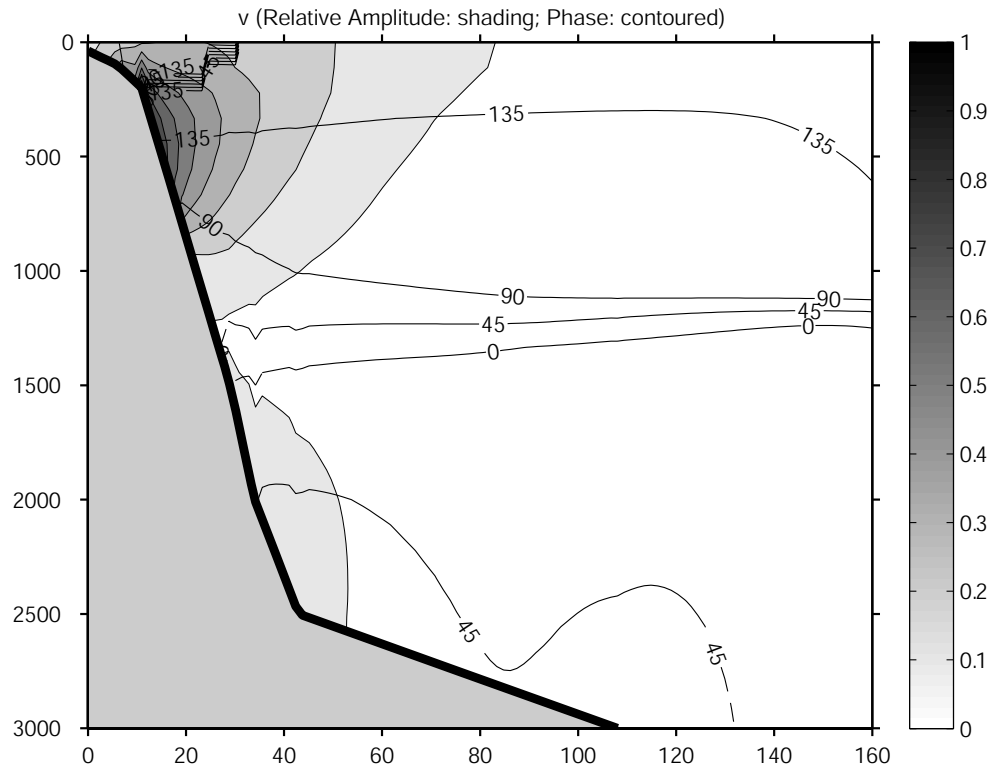

Figure 4: First mode alongshore velocity modal structures for southeastern Africa section $\mathrm{K}$ with no mean alongshore flow, and $r=0.05 \mathrm{~cm} / \mathrm{sec}$. The points are shown by small circles on Figure 1. (a) $\omega_{R}=7.59 \times 10^{-7} \mathrm{sec}^{-1}, \omega_{I}=10.42 \times 10^{-7} \mathrm{sec}^{-1}$ and $l=1 \times 10^{-9}$ $\mathrm{cm}^{-1}$. (b) $\omega_{R}=44.76 \times 10^{-7} \mathrm{sec}^{-1}, \omega_{I}=8.48 \times 10^{-7} \mathrm{sec}^{-1}$ and $l=16 \times 10^{-9} \mathrm{~cm}^{-1}$. 


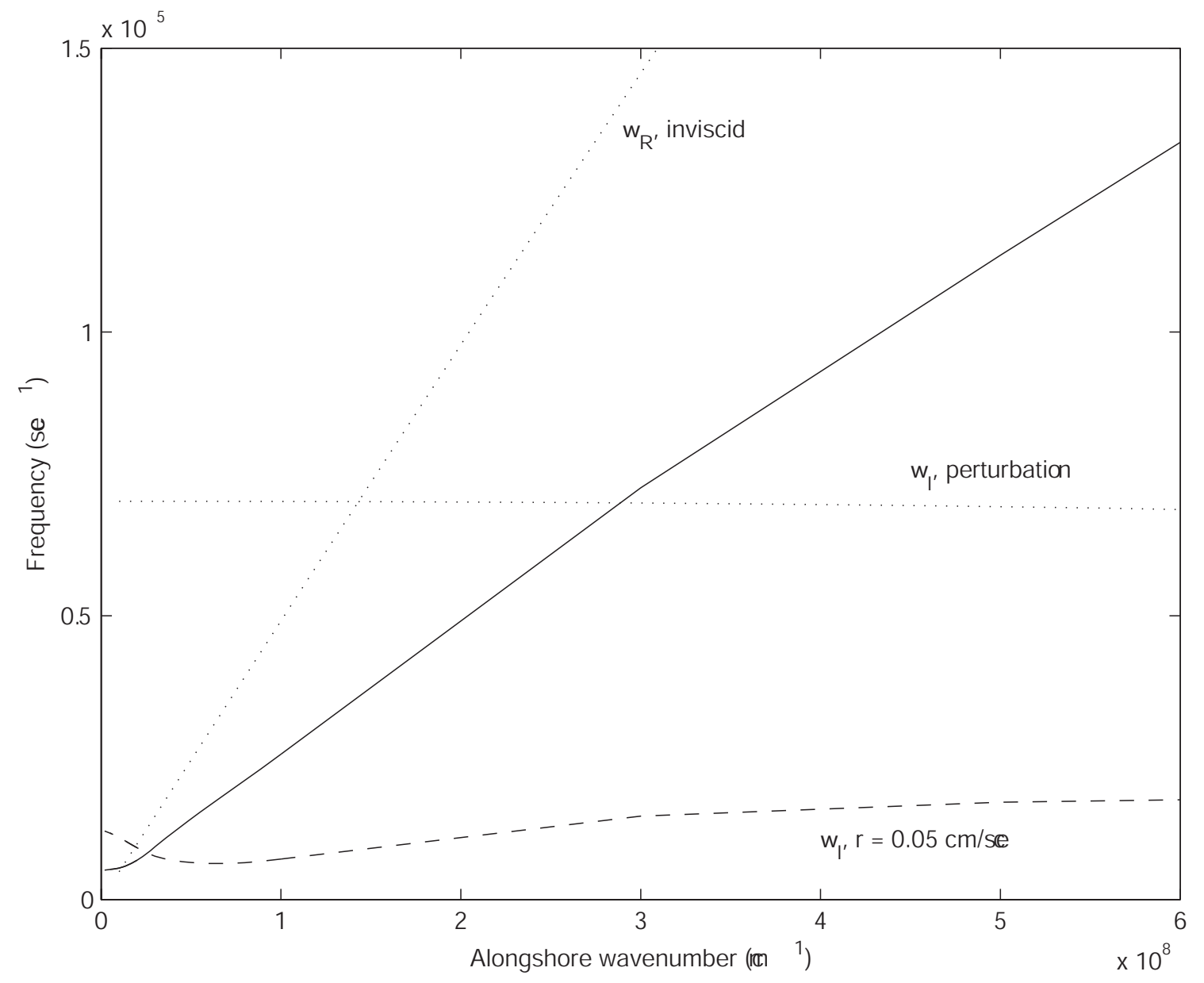

Figure 5: First mode dispersion curves with $r=0.05 \mathrm{~cm} / \mathrm{sec}$ for stratification and topography representative of the Dongara line west of Australia with no mean alongshore flow. Perturbation results are shown by a dotted line. For the calculated results, the real part of frequency $\omega_{R}$ is shown as a solid line, and the imaginary part of frequency $\omega_{I}$ as a dashed line. 

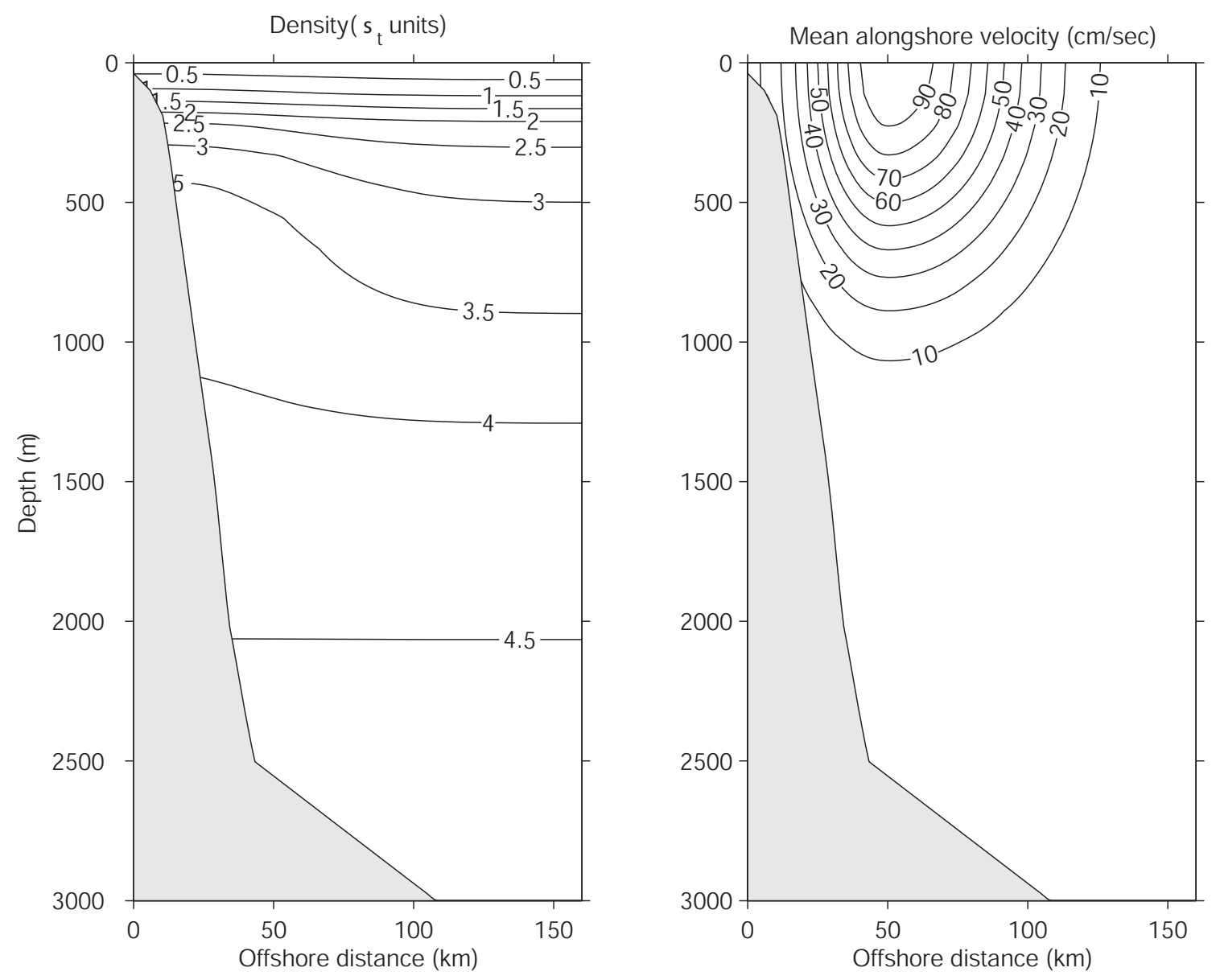

Figure 6: Mean stratification ( $\sigma_{t}$ units minus a constant background) and mean alongshore velocity $(\mathrm{cm} / \mathrm{sec})$ for conditions representative of southeastern African section $\mathrm{K}$ (velocity is opposite to the true Agulhas so as to compensate for the use of $f>0$ ). 


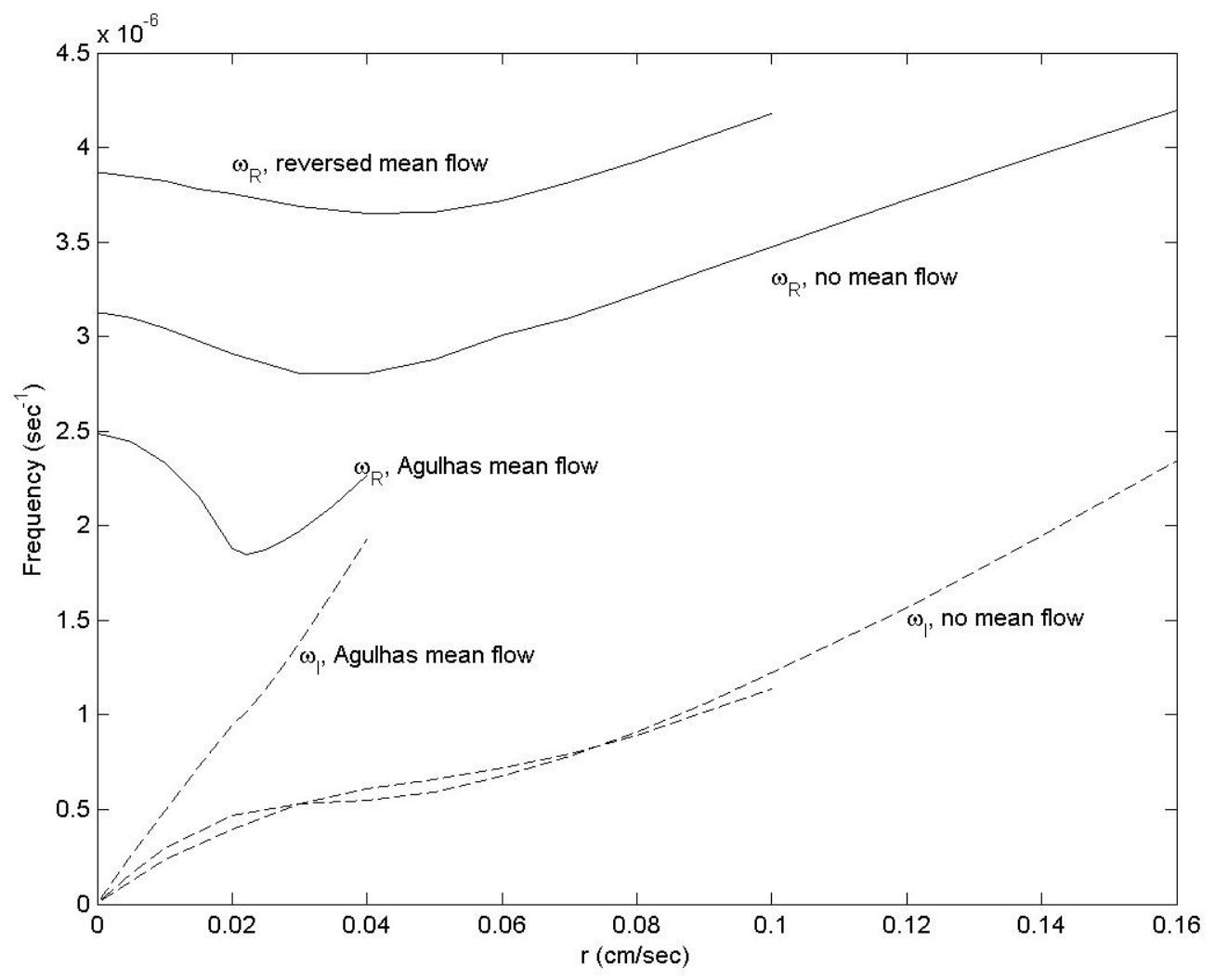

Figure 7: First mode wave frequency for $l=1 \times 10^{-8} \mathrm{~cm}^{-1}$ as a function of resistance parameter $r$ for mean alongshore flow opposed to wave propagation ("Agulhas case"), no mean flow, and mean flow in the same direction ("reversed mean flow") as coastal-trapped wave propagation. Real part of frequency $\omega_{R}$ is shown by solid lines, and imaginary part $\omega_{I}$ by dashed lines. 
a)

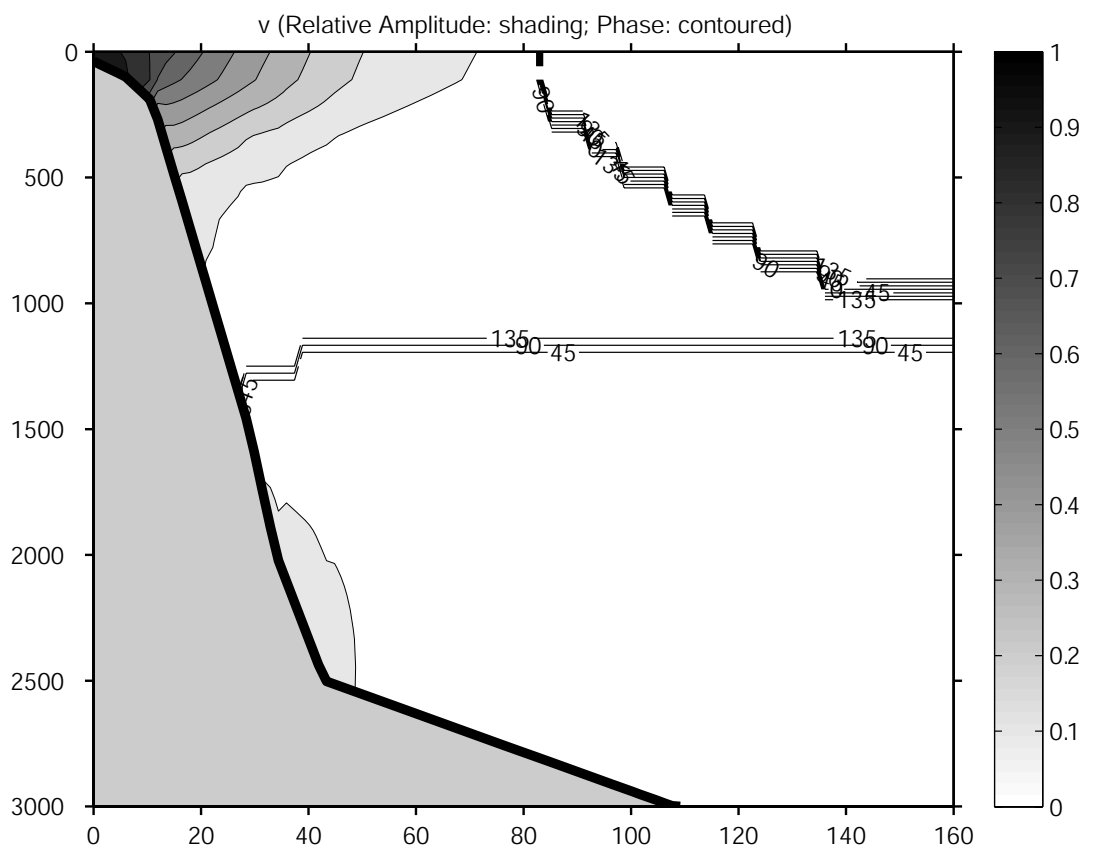

b)

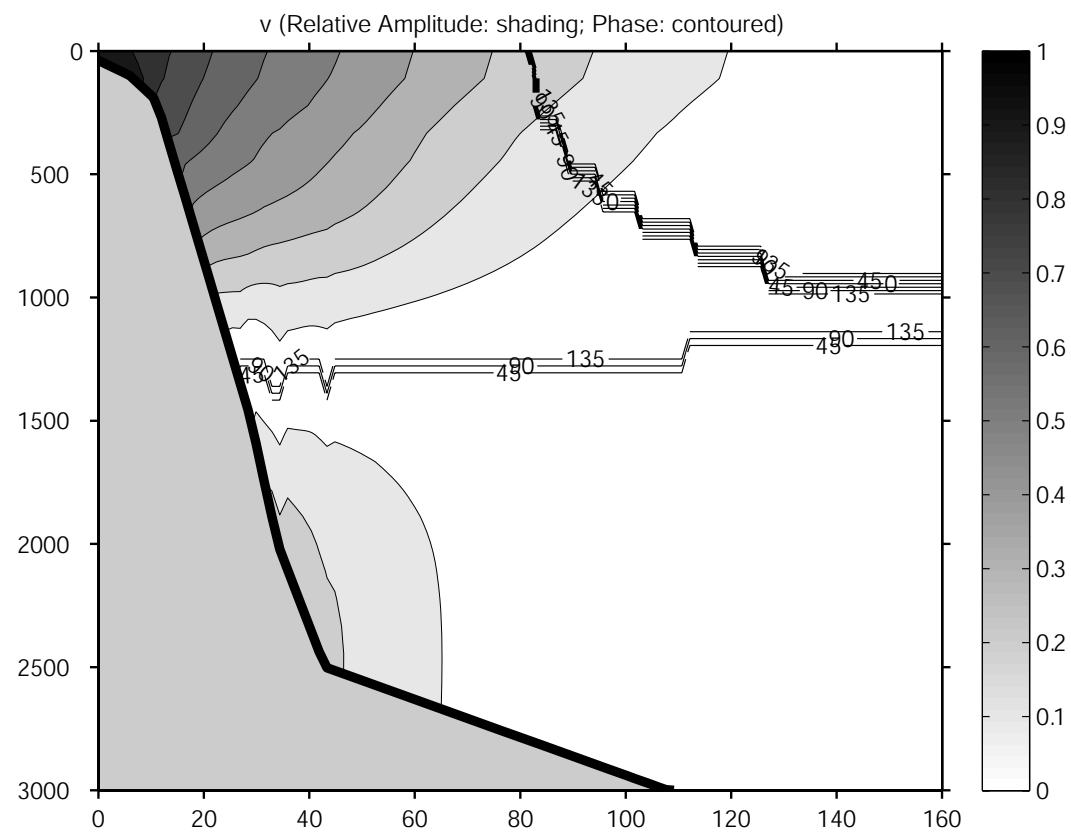

Figure 8: First mode alongshore velocity modal structures for $r=0, l=1 \times 10^{-8} \mathrm{~cm}^{-1}$, and conditions representative of southeastern Africa line. The plotting convention is as in Figure 3. (a) with mean flow as in Figure 6, opposed to coastal trapped wave propagation; (b) with mean flow opposite to that in Figure 6, i.e., in the same direction as coastal-trapped wave propagation. 


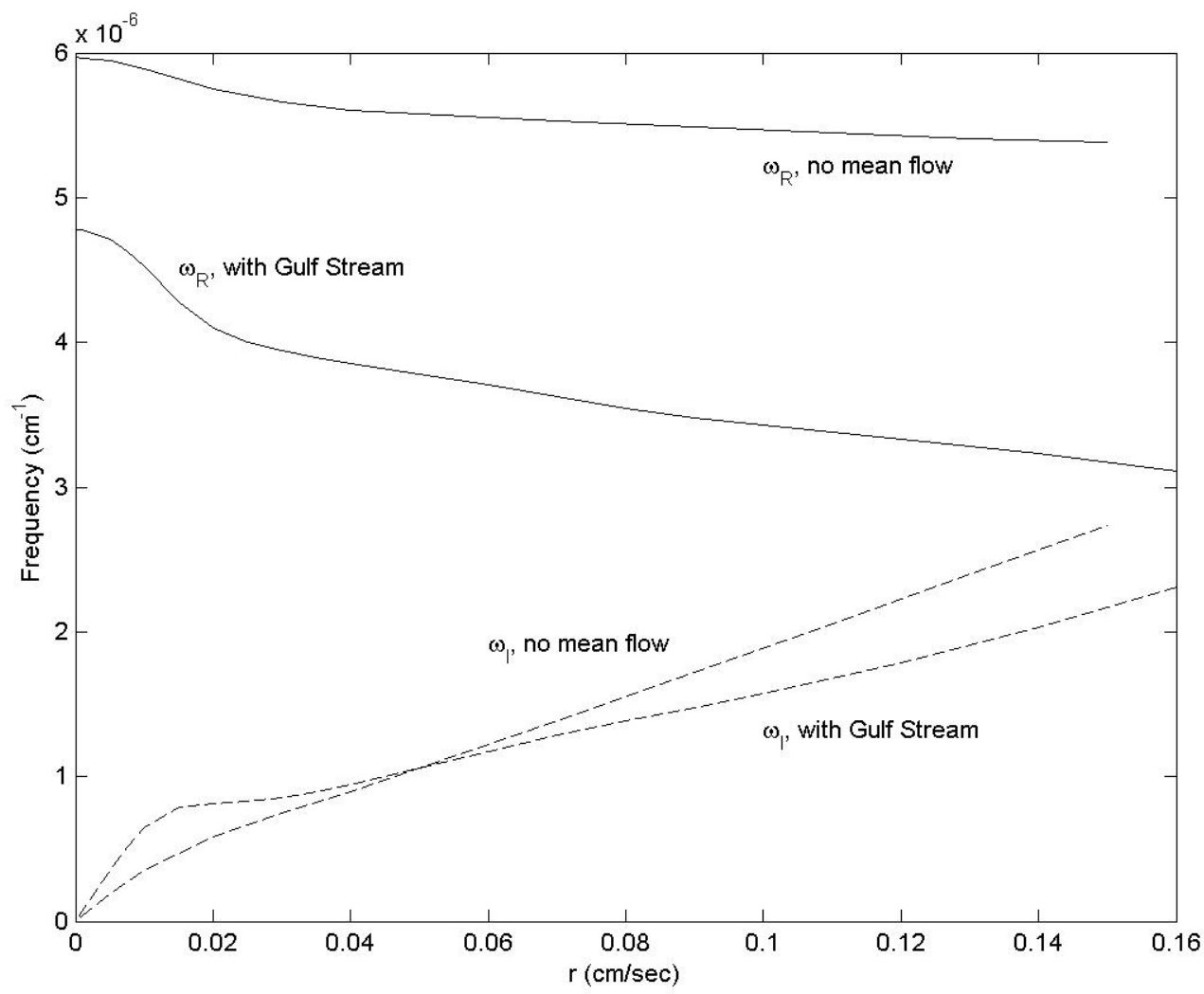

Figure 9: First mode wave frequency as a function of bottom resistance parameter $r$ for conditions representative of the U.S. South Atlantic Bight and $l=1 \times 10^{-8} \mathrm{~cm}^{-1}$. Results are shown for no mean alongshore flow, and with a Gulf Stream present. Solid lines are the real part of frequency $\omega_{R}$, and dashed lines for the imaginary part of frequency $\omega_{I}$. 